\title{
ASO Visual Abstract: A Prospective Study Evaluating the Accuracy of Indocyanine Green (ICG) Fluorescence Compared with Radioisotope for Sentinel Lymph Node (SIn) Detection in Early Breast Cancer
}

\author{
Dorin Dumitru, MD, FRCS ${ }^{1,2}$, Sujit Ghanakumar, $\mathrm{MD}^{3}$, Elena Provenzano, MD ${ }^{3}$, and John R. Benson, MD, FRCS ${ }^{3,4}$ \\ ${ }^{1}$ Breast Services, Breast Unit Castle Hill Hospital, Hull University Teaching Hospitals NHS Trust, Cottingham, UK; ${ }^{2}$ Hull \\ York Medical School, Hull, UK; ${ }^{3}$ Cambridge Breast Unit, Cambridge University Hospitals NHS Foundation Trust, \\ Cambridge, UK; ${ }^{4}$ School of Medicine, Anglia Ruskin University, Cambridge, UK
}

This prospective study assessed the performance of indocyanine green (ICG) fluorescence for sentinel lymph node (SLN) identification compared with the standard radioisotope tracer agent. Overall rate of identification was $98.7 \%$ with ICG being noninferior for detection of SLNs compared with radioisotope (https://doi.org/10.1245/s10434-021-11255-9).

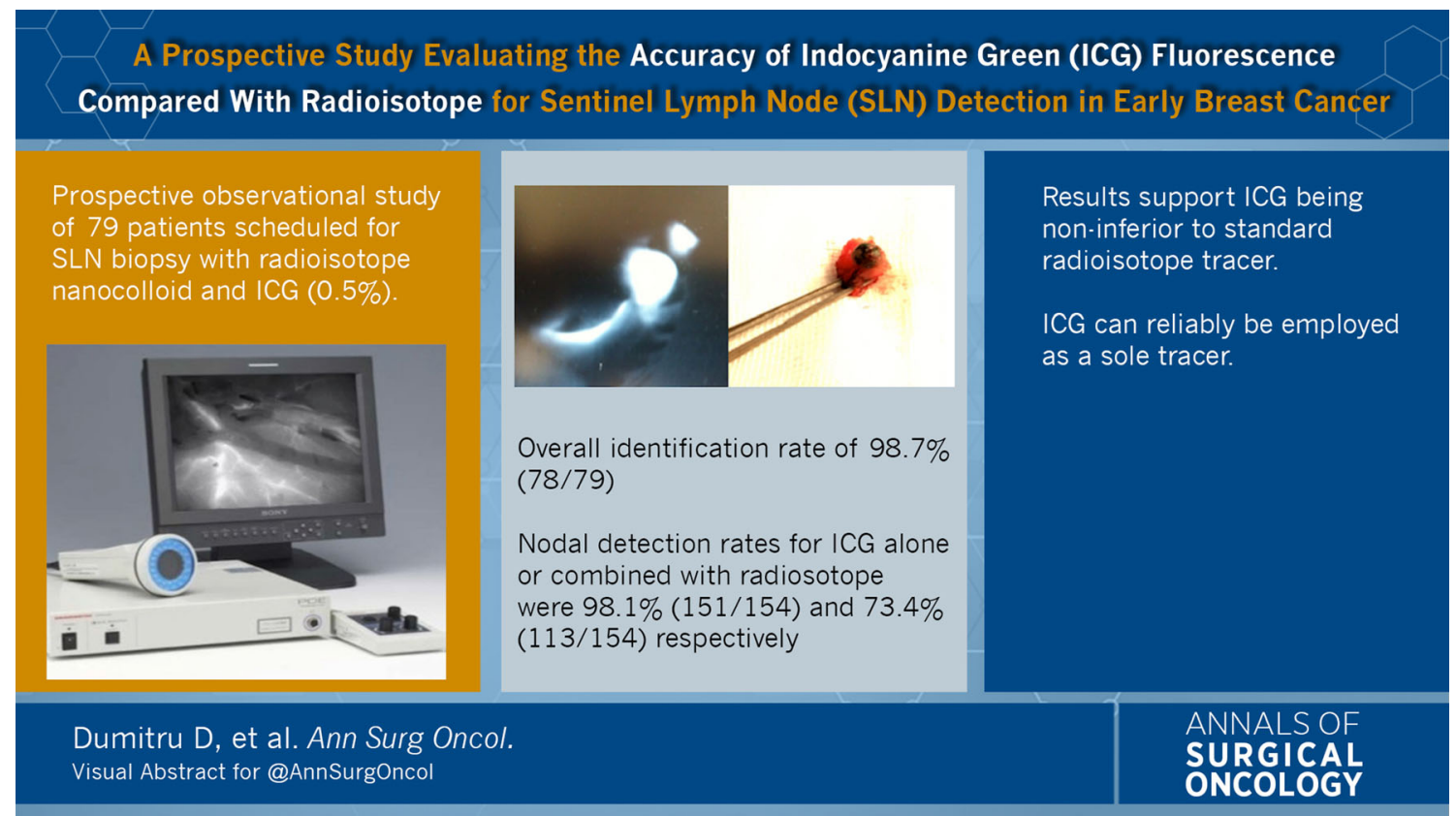

(C) Society of Surgical Oncology 2022

DISCLOSURE The authors declare no conflicts of interest.

Dorin Dumitru, MD, FRCS

e-mail: dorin.dumitru@nhs.net; drdumitrudorin@gmail.com

Publisher's Note Springer Nature remains neutral with regard to jurisdictional claims in published maps and institutional affiliations. 